\title{
The SNMMI Procedure Standard/EANM Practice Guideline for Gastrointestinal Bleeding Scintigraphy 2.0
}

\author{
Hung Q. Dam ${ }^{1}$ (Chair), David C. Brandon², Vesper V. Grantham³ ${ }^{3}$ Andrew J. Hilson ${ }^{4}$, Douglas M. Howarth ${ }^{5}$, \\ Alan H. Maurer6, Michael G. Stabin ${ }^{7}$, Mark Tulchinsky ${ }^{8}$, Harvey A. Ziessman ${ }^{9}$, and Lionel S. Zuckier ${ }^{10}$ \\ ${ }^{1}$ Christiana Care Health System, Newark, Delaware; ${ }^{2}$ Emory University, Atlanta, Georgia; ${ }^{3}$ University of Oklahoma Health Sciences \\ Center, Oklahoma City, Oklahoma; ${ }^{4}$ Royal Free Hospital, London, England; ${ }^{5}$ Newcastle Nuclear Medicine, Warners Bay, Australia; \\ ${ }^{6}$ Temple University, Philadelphia, Pennsylvania; ${ }^{7}$ Vanderbilt University, Nashville, Tennessee; ${ }^{8}$ Penn State Milton S. Hershey Medical \\ Center, Hershey, Pennsylvania; ${ }^{9}$ Johns Hopkins University, Baltimore, Maryland; and ${ }^{10}$ Ottawa Hospital, Ottawa, Canada
}

\begin{abstract}
CE credit: For CE credit, you can access the test for this article, as well as additional JNMT CE tests, online at https://www.snmmilearningcenter.org. Complete the test online no later than December 2016. Your online test will be scored immediately. You may make 3 attempts to pass the test and must answer $80 \%$ of the questions correctly to receive $1.0 \mathrm{CEH}$ (Continuing Education Hour) credit. SNMMI members will have their CEH credit added to their VOICE transcript automatically; nonmembers will be able to print out a CE certificate upon successfully completing the test. The online test is free to SNMMI members; nonmembers must pay $\$ 15.00$ by credit card when logging onto the website to take the test.
\end{abstract}

\section{PREAMBLE}

The Society of Nuclear Medicine and Molecular Imaging (SNMMI) is an international scientific and professional organization founded in 1954 to promote the science, technology, and practical application of nuclear medicine. Its 18,000 members are physicians, technologists, and scientists specializing in the research and practice of nuclear medicine. In addition to publishing journals, newsletters, and books, the SNMMI also sponsors international meetings and workshops designed to increase the competencies of nuclear medicine practitioners and to promote new advances in the science of nuclear medicine. The European Association of Nuclear Medicine (EANM) is a professional nonprofit medical association that facilitates communication worldwide between individuals pursuing clinical and research excellence in nuclear medicine. The EANM was founded in 1985.

The SNMMI/EANM will periodically define new standards/ guidelines for nuclear medicine practice to help advance the science of nuclear medicine and to improve the quality of service to patients. Existing standards/guidelines will be reviewed for revision or renewal, as appropriate, on their fifth anniversary or sooner, if indicated. As of February 2014, the SNMMI guidelines will now be referred to as procedure standards. Any previous practice guideline or procedure guideline that describes how to perform a procedure is now considered an SNMMI procedure standard.

Received Aug. 29, 2014; accepted Aug. 29, 2014

For correspondence or reprints contact: Hung Q. Dam, Section of Nuclear Medicine, Christiana Care Health System, 4755 Ogletown-Stanton Rd., Newark, DE 19718.

E-mail: hdam@christianacare.org

COPYRIGHT (c) 2014 by the Society of Nuclear Medicine and Molecular Imaging, Inc.

DOI: $10.2967 /$ jnmt.114.147959
Each standard/guideline, representing a policy statement by the SNMMI/EANM, has undergone a thorough consensus process in which it has been subjected to extensive review. The SNMMI/EANM recognizes that the safe and effective use of diagnostic nuclear medicine imaging requires specific training, skills, and techniques, as described in each document.

The SNMMI and EANM have written and approved these standards/guidelines to promote the use of nuclear medicine procedures with high quality. These standards/ guidelines are intended to assist practitioners in providing appropriate nuclear medicine care for patients. They are not inflexible rules or requirements of practice and are not intended, nor should they be used, to establish a legal standard of care. For these reasons and those set forth below, the SNMMI/EANM cautions against the use of these standards/ guidelines in litigation in which the clinical decisions of a practitioner are called into question.

The ultimate judgment regarding the propriety of any specific procedure or course of action must be made by medical professionals taking into account the unique circumstances of each case. Thus, there is no implication that an approach differing from the standards/guidelines, standing alone, is below the standard of care. To the contrary, a conscientious practitioner may responsibly adopt a course of action different from that set forth in the standards/ guidelines when, in the reasonable judgment of the practitioner, such course of action is indicated by the condition of the patient, limitations of available resources, or advances in knowledge or technology subsequent to publication of the standards/guidelines.

The practice of medicine involves not only the science but also the art of dealing with the prevention, diagnosis, alleviation, and treatment of disease. The variety and complexity of human conditions make it impossible to always reach the most appropriate diagnosis or to predict with certainty a particular response to treatment. Therefore, it should be recognized that adherence to these standards/guidelines will not ensure 
an accurate diagnosis or a successful outcome. All that should be expected is that the practitioner will follow a reasonable course of action based on current knowledge, available resources, and the needs of the patient to deliver effective and safe medical care. The sole purpose of these standards/guidelines is to assist practitioners in achieving this objective.

\section{INTRODUCTION}

Gastrointestinal bleeding scintigraphy (GIBS) is a noninvasive study that is performed on patients with suspected gastrointestinal bleeding to determine whether the bleeding is active, to localize the bleeding site, and to approximate the bleeding volume for prognostic purposes. These characteristics can be challenging to identify but are important for initiation of prompt and effective therapy. The clinical signs and symptoms and laboratory indicators of gastrointestinal hemorrhage are often unreliable and misleading regarding the presence of active bleeding. There is frequently a marked lag between the onset of bleeding and the clinical findings. Melena is a sequela of earlier bleeding that could have stopped, and blood may remain in the bowel for hours before being evacuated. Orthostatic hypotension and tachycardia may be detected more acutely but are insensitive and nonspecific. A decrease in hematocrit and an elevation in serum blood urea nitrogen generally lag behind a bleeding episode, which may have ended hours earlier.

GIBS enables continuous monitoring of the entire gastrointestinal tract for up to approximately $24 \mathrm{~h}$ (1). The ability to perform continuous imaging increases the likelihood of detection of intermittent bleeding over other techniques that are limited to only a single time point or periodic sampling (2-6). Furthermore, GIBS is a procedure that does not require any patient preparation, can be performed with standard nuclear medicine instrumentation, and is well tolerated even in patients who are acutely ill.

Gastrointestinal bleeding may be classified as upper gastrointestinal bleeding (above the ampulla of Vater and within reach of esophagogastroduodenoscopy), mid gastrointestinal bleeding (small bowel from the ampulla of Vater to the terminal ileum, which can be evaluated by capsule endoscopy or double-balloon enteroscopy), or lower gastrointestinal bleeding in the colon, which can be evaluated by colonoscopy (7). Common causes of upper gastrointestinal bleeding include esophageal varices, gastric and duodenal ulcers, gastritis, esophagitis, Mallory-Weiss tears, and neoplasms. The most common causes of mid gastrointestinal bleeding are angiodysplasia, neoplasms, Crohn disease, diverticula, and Meckel diverticulum. Common causes of lower gastrointestinal bleeding include angiodysplasia, diverticulosis, benign and malignant bowel neoplasms, adenomatous polyps, inflammatory bowel disease, and infectious bowel disease.

Although this standard/guideline is focused on the use of ${ }^{99 m}$ Tc-labeled autologous red blood cells (99m Tc-RBCs) for detection of sites of gastrointestinal bleeding, the methods described in this standard/guideline may be applicable to localizing occult bleeding elsewhere in the body.

\section{GOALS}

The purpose of this standard/guideline is to assist nuclear medicine practitioners in recommending, performing, interpreting, and reporting the results of GIBS in adults and children. The goals of GIBS are to determine whether the patient is actively bleeding, to localize the bleeding bowel segment, and to estimate the rate of blood loss, which allows for treatment planning and risk stratification.

\section{DEFINITIONS}

GIBS is a diagnostic radionuclide imaging study performed with ${ }^{99 \mathrm{~m}} \mathrm{Tc}-\mathrm{RBC}$ s that detects active bleeding into the gastrointestinal lumen. Gastrointestinal bleeding can be either occult (detected only on guaiac fecal occult blood testing) or overt (with clinical signs and symptoms such as melena or hematochezia). Obscure gastrointestinal bleeding can be either overt or occult and is defined as persistent or recurrent gastrointestinal bleeding from an unknown source despite an exhaustive work-up including esophagogastroduodenoscopy, colonoscopy, or other initial studies (8).

\section{COMMON CLINICAL INDICATIONS}

GIBS is commonly indicated for identifying an active gastrointestinal bleeding site in patients with overt gastrointestinal bleeding. GIBS should not be performed on patients with chronic occult gastrointestinal bleeding because the guaiac fecal occult blood test may detect bleeding at rates well below those necessary to be identified on GIBS.

GIBS is indicated primarily for overt mid or lower gastrointestinal bleeding, specifically when an upper gastrointestinal bleed has been excluded by nasogastric lavage (9). In this scenario, GIBS can be used as an early diagnostic study for gastrointestinal bleeding especially for hospitalized patients or patients in the emergency department (911). GIBS can be beneficial when other studies require lengthy patient preparation or are contraindicated. Although GIBS can also identify overt upper gastrointestinal bleeding, usually the first procedure performed to confirm upper gastrointestinal bleeding is nasogastric lavage, followed by esophagogastroduodenoscopy to identify and treat suspected overt upper gastrointestinal bleeding.

GIBS is also indicated to help identify the source of obscure overt gastrointestinal bleeding. Two standards/ guidelines have removed GIBS from the diagnostic algorithm for obscure overt gastrointestinal bleeding $(12,13)$. However, most studies have shown that GIBS can help localize the obscure overt bleeding site in these patients (14-21).

Among some of the other common clinical indications for GIBS are stratifying risk in patients with gastrointestinal bleeding (22-28), directing timely diagnostic angiography, and assisting in plans for surgical or other interventional procedures $(6,29-34)$. 


\section{QUALIFICATIONS AND RESPONSIBILITIES OF PERSONNEL (IN THE UNITED STATES)}

Refer to the SNMMI Procedure Standard for General Imaging.

\section{PROCEDURE/SPECIFICATIONS OF THE EXAMINATION}

\section{A. Request}

At the time of the request, it is important for the referring clinician to have a management plan in place before GIBS. Through early coordination of clinical services (such as interventional radiology, gastroenterology, or surgery), the patient can be directed promptly to the next diagnostic or therapeutic procedure if GIBS has positive results (35). Any unnecessary delay increases the likelihood of negative angiography findings, as bleeding often stops spontaneously (33).

All pertinent clinical information should be reviewed before the study is started. Information specifically related to GIBS may include the following.

1. Clinical signs of gastrointestinal bleeding (frequency, volume, and character [hematochezia, melena, or hematemesis]; current and recent hemoglobin, hematocrit, and blood urea nitrogen findings; number of recent transfusions; current blood pressure and heart rate; presence of orthostatic vital signs)

2. History of prior abdominal or pelvic surgeries

3. Diagnostic studies (nasogastric tube aspiration, esophagogastroduodenoscopy, capsule endoscopy, double-balloon enteroscopy, sigmoidoscopy or colonoscopy, prior GIBS, angiography, CT enterography/ angiography)

4. Therapeutic interventions (endoscopic epinephrine injection, coagulation [by cautery, heater probe, laser, or argon plasma coagulator] or mechanical therapy [clips, bands, or detachable loops], angiographic embolization, selective arterial infusion of vasoconstrictors such as vasopressin)

5. Current medications

6. Factors that may decrease RBC radiolabeling efficiency $(3,36,37)$ (drug interactions [iodinated contrast material, chemotherapy, digoxin, calcium channel blockers, cyclosporin, metronidazole, ranitidine, propanolol, quinidine, dipyridamole, and heparin]; low hematocrit; sickle-cell disease or thalassemia; circulating antibodies from prior transfusion or transplantation)

7. Oral contrast agents such as barium used for other gastrointestinal imaging studies (can cause photopenic artifacts (38) but are not an absolute contraindication for GIBS (39))

\section{B. Patient preparation and precautions}

Patients with gastrointestinal bleeding who are considered hemodynamically unstable should be monitored by a physician or nurse while in the nuclear medicine department.
Reinjection of radiolabeled blood poses the risk of incorrect administration to a wrong patient. Written policies must be in place, with special safeguards regarding the handling and administration of blood to eliminate any possibility of administration to the wrong patient, particularly when two or more RBC labeling studies are performed simultaneously. Universal precautions must be followed to avoid staff exposure to blood products. Refer to the SNMMI Procedure Standard for Use of Radiopharmaceuticals.

Fasting is not required for GIBS. However, fasting may be required for subsequent procedures such as angiography or surgery.

Patients should be instructed to void immediately before imaging so they are comfortable during a potentially long scan and to facilitate scan interpretation.

\section{Radiopharmaceuticals}

Historically, two radiopharmaceuticals have been used

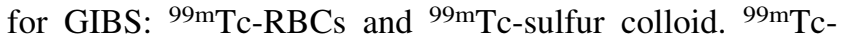
RBCs are the radiopharmaceutical of choice for performing GIBS because of an intravascular half-life that allows continuous imaging of the gastrointestinal tract over many hours (40-42). The superior clinical utility of ${ }^{99 \mathrm{~m}} \mathrm{Tc}-\mathrm{RBCs}$ over early studies using ${ }^{99 \mathrm{~m}} \mathrm{Tc}$-sulfur colloid has been demonstrated in comparison studies (40-42).

${ }^{99} \mathrm{~m}$ Tc-RBCs can detect gastrointestinal bleeding at a rate of as low as $0.04 \mathrm{~mL} / \mathrm{min}$ in experimental animal models and $0.1 \mathrm{~mL} / \mathrm{min}$ in clinical studies $(28,43)$. High efficiency of RBC labeling with minimal unbound ${ }^{99 \mathrm{~m}} \mathrm{Tc}$ is critical to producing optimal, artifact-free images. Three methods are available to label RBCs: in vitro, modified in vivo, and in vivo. The in vitro method using a commercially available kit yields the highest labeling efficiency ( $\geq 95 \%$ ) and is the method of choice $(44,45)$. A further advantage of the in vitro method is that a sample can be evaluated for radiolabeling efficiency with a centrifuge method as described in the manufacturer's package insert. Additionally, if radiolabeling is substandard because of a drug interaction, low hematocrit level, or other factor (section VI.A.6), or because of a procedural deviation, a salvage technique may be attempted (46). This procedure involves transferring the in vitro ${ }^{99 \mathrm{~m}} \mathrm{Tc}-\mathrm{RBCs}$ into a sterile $15-\mathrm{mL}$ polypropylene centrifuge tube and centrifuging at $400 \mathrm{~g}$ for $5 \mathrm{~min}$. The supernatant is then removed with a sterile pipette, and the ${ }^{99 \mathrm{~m}} \mathrm{Tc}-\mathrm{RBCs}$ are resuspended in $2 \mathrm{~mL}$ of $0.9 \%$ sodium chloride. If the radiochemical purity of the ${ }^{99 \mathrm{~m} T c-R B C s}$ is then more than $95 \%$ and adequate radioactivity remains, the salvage is deemed successful. The modified in vivo label (90\% labeling efficiency) can serve as an alternative when the in vitro method is not available (47-49). The in vivo method is not recommended because of suboptimal labeling and a higher likelihood of free ${ }^{99 \mathrm{~m}} \mathrm{Tc}$-pertechnetate. However, the in vivo method may be needed for patients who, because of religious convictions or other reasons, will not accept injection of blood. 
The recommended administered activity of ${ }^{99 \mathrm{~m}} \mathrm{Tc}-\mathrm{RBCs}$ is $555-1,110 \mathrm{MBq}(15-30 \mathrm{mCi})$ in adults. In children under $18 \mathrm{y}$ old, the recommended administered activity is based on the EANM Pediatric Dosage Card, which uses a baseline activity of $56 \mathrm{MBq}(1.51 \mathrm{mCi})$ multiplied by a weight-based multiple $(49,50)$. The resulting minimum administered activity is $80 \mathrm{MBq}(2.16 \mathrm{mCi})$ for a $3-\mathrm{kg}$ patient and the maximum administered activity is $784 \mathrm{MBq}(21.19 \mathrm{mCi})$ for a $68-\mathrm{kg}$ patient.

\section{Protocol/image acquisition}

1. Image acquisition

In the supine position, anterior images of the abdomen and pelvis are acquired (section VIII specifies equipment). A minimum image matrix of $128 \times 128$ is recommended. Any items on the patient that may produce imaging artifacts should be removed or moved out of the field of view. Care should be taken to keep patients' upper extremities from overlying the abdomen and pelvis during imaging as the upper extremities can obscure findings and their movement can cause artifacts.

After the injection of ${ }^{99 \mathrm{~m}} \mathrm{Tc}-\mathrm{RBCs}$, rapid image acquisition at a rate of 1 frame per 1-3 s for $60 \mathrm{~s}$ (nuclear angiography) can be performed to visualize the distribution of vascular structures and may help differentiate between blood pool activity and bleeding on later images. However, these angiographic images seldom add to the overall study result and are considered optional.

Immediately after the angiographic study, dynamic imaging should be performed. Serial intermittent static images are not recommended. The maximum recommended frame rate should not exceed 1 frame per $60 \mathrm{~s}$. As the frame rate becomes longer, the temporal resolution of the scan decreases, possibly leading to inaccurate localizing of the bleeding source.

Since intraluminal blood promotes rapid bowel peristalsis and movement of blood antegrade or retrograde from the bleeding site, faster frame rates such as 1 frame per 10-20 s allow for higher temporal resolution to better localize the gastrointestinal bleeding site (51). On the other hand, a small volume of intraluminal blood or slow gastrointestinal bleeding may be more difficult to detect when fast frame rates are used because of lower count densities (51). This shortcoming can be compensated by reformatting the acquired study into longer frames $(51,52)$. Therefore, reformatting is recommended when using fast frame rates. However, the optimal dynamic frame rate for GIBS has not been established because there are no published clinical studies that have compared these various acquisition techniques.

Acquiring the dynamic images in 10- to 15 -min sequences may facilitate review of these images by the physician because one series can be reviewed while subsequent sequences are still being acquired.
Since gastrointestinal bleeding occurs intermittently, the patient should be imaged continuously for as long as practical to identify the bleeding source (10,34,53-55). Initial imaging for a minimum of $60 \mathrm{~min}$ is recommended if no gastrointestinal bleeding is detected $(14,19,42,52,56)$. If abnormal focal RBC activity is detected, image acquisition should continue for a sufficient time to confidently identify the bleeding site. Accurate localization of the bleeding site is dependent on identification of the initial location of extravasated blood and movement of blood from that site within the bowel lumen. Increased imaging time may be particularly needed to differentiate a smallbowel bleed from a large-bowel bleed. SPECT/CT may also be helpful in this context (57).

Urine activity in a full bladder may obscure sigmoid or rectal bleeding on a standard anterior view. Lateral, posterior, or subpubic views may help in identifying activity in the rectum that would otherwise not be detected because of bladder activity or softtissue attenuation. The entire abdomen and pelvis must be examined before one can conclude that no gastrointestinal bleeding is detected. When a dualhead camera is used, simultaneous imaging in the anterior and posterior views may improve the sensitivity for detecting rectal bleeding. Furthermore, lateral views are helpful in differentiating anterior vascular penile activity (which can move or change in intensity during imaging) from bleeding in the more posteriorly located rectosigmoid colon (35).

If the patient has a bowel movement during the scan, the stool should be imaged to assess for radioactivity. The presence of radioactivity in the stool would only confirm active gastrointestinal bleeding and does not necessarily localize the origin of the bleeding. If gastric activity is visualized, an anterior image of the head and neck should be obtained to evaluate for possible thyroid and salivary gland activity. Activity at these sites suggests the presence of free ${ }^{99 \mathrm{~m}} \mathrm{Tc}$-pertechnetate as the cause of the gastric activity rather than gastric bleeding.

If no bleeding site is identified on the initial images, delayed images can be acquired by rescanning the patient for up to $24 \mathrm{~h}$, especially if there is clinical evidence of recurrent gastrointestinal bleeding (section F). All delayed images should be acquired using the same dynamic method as the initial images. If available, the same camera as used for the initial images should also be used for the delayed images.

2. Processing

If motion correction software is available, it can minimize the effects of patient movement. Computer subtraction of background activity of early images from later frames in the imaging sequence has the following limitations: the patient must remain still during the examination or motion correction software 
must be applied, and the biodistribution of the 99m Tc-RBCs should be similar between the early frames and any image to be subtracted $(51,58-62)$. Failure to control these factors can cause false-positive findings.

\section{E. Interpretation}

Accurate interpretation of GIBS requires knowledge of normal and abnormal anatomic variations in the abdomen and pelvis. Comparison with anatomic imaging studies (CT, MR imaging, or radiographs) of the abdomen and pelvis is useful in establishing gastrointestinal tract and vascular anatomy. Review of the dynamic images in cinematic display is essential to detect subtle gastrointestinal bleeding and avoid inaccurate localization of the bleeding site $(1,2,52,63,64)$. Proper adjustment of gray-scale levels on the interpreting physician's computer display also facilitates the detection of subtle abnormalities.

$99 \mathrm{~m}$ Tc-RBCs are rapidly distributed within the vascular space, including the heart, liver, spleen, and great vessels. Some excreted radioactivity may be seen in the urinary tract because of small amounts of free ${ }^{99 \mathrm{~m}}$ Tc-pertechnetate and other ${ }^{99 \mathrm{~m}} \mathrm{Tc}$ moieties even when in vitro labeling is used (65). The initial angiographic-phase images rarely reveal the site of rapid gastrointestinal bleeding, which may be difficult to localize on the subsequent dynamic images, or a vascular blush in neoplasms, arteriovenous malformations, or angiodysplasia $(52,66,67)$.

The key diagnostic criteria for scintigraphic gastrointestinal bleeding are the appearance of activity outside the expected anatomic blood pool structures, a change in the intensity of activity on consecutive images, and movement of activity in a pattern consistent with bowel. All 3 of these criteria must be satisfied to diagnose a site of active gastrointestinal bleeding.

Small-bowel bleeding usually can be distinguished from large-bowel bleeding by its rapid curvilinear movement and usual central location in the abdomen or pelvis. In comparison, large-bowel bleeding has a more linear pattern and typically occurs in the periphery of the abdomen or pelvis. Large-bowel bleeding can also be visualized as an S-shaped pattern in the central pelvis conforming to the distribution of the rectosigmoid colon. The origin of the site of gastrointestinal bleeding should be reported as the location of the initial site of detected activity rather than the most intense, largest, or most proximal site of activity.

GIBS may be used to estimate the severity of the bleeding. Factors associated with a low bleeding rate include visualization of blood after $1 \mathrm{~h}$, activity less intense than that in the liver, and shorter bleeding durations (28). Higher bleeding rates are associated with the early appearance of blood in the bowel, intense activity equal to or greater than that in the liver, and a longer duration of bleeding (28).

\section{F. Sources of error}

Delayed imaging after a period of nonimaging can be problematic because bowel activity seen immediately on the first frame of delayed images indicates merely that bleeding originating elsewhere in the gastrointestinal tract has occurred during the interim; the activity should not be misinterpreted as the bleeding site. Therefore, the location of delayed bowel activity should be reported as the bleeding site only when an actual episode of RBC extravasation on dynamic imaging is observed. Digital subtraction may be helpful for identification of the actual site of active bleeding when delayed images have been obtained (section D2).

The benefits of delayed imaging, including its effect on patient management such as transfusion requirements, referrals to angiography or surgery, and clinical outcomes, are controversial $(68,69)$. Many investigators have shown that delayed images are not as accurate as early images in localizing the site of gastrointestinal bleeding $(30,34,56,68,70-72)$. Some authors advocate imaging patients for as long as possible during the initial phase rather than performing routine delayed imaging at arbitrary intervals hours after injection $(10,56)$. Other investigators have demonstrated usefulness for delayed imaging in detecting a site of intermittent gastrointestinal bleeding not seen on the initial phase $(1,40,53,55,61,72-74)$. Therefore, delayed imaging is considered optional.

There are some pitfalls to the interpretation of GIBS images.

1. Free ${ }^{99 \mathrm{~m} T \mathrm{Tc}-\text { pertechnetate }}$

Free ${ }^{99 \mathrm{~m}}$ Tc-pertechnetate can be visualized in the upper gastrointestinal tract secondary to swallowed salivary gland activity or excreted gastric mucosal activity. Since free ${ }^{99 \mathrm{~m}} \mathrm{Tc}$-pertechnetate can move from the stomach into the small bowel over time, it can be mistaken for upper gastrointestinal bleeding. Images of the neck to detect thyroid and salivary gland activity should be obtained to confirm the presence of free ${ }^{99 \mathrm{~m}}$ Tc-pertechnetate as a source of an artifact.

Urinary tract activity due to free ${ }^{99 \mathrm{~m}} \mathrm{Tc}$-pertechnetate may be seen in the abdomen or pelvis.

2. Increased RBC activity due to other causes

In the reproductive system, penile blood pool can be mistaken for rectal bleeding (75). Obtaining lateral images or changing the position of the penis can distinguish penile activity from rectal bleeding (35). In addition, variable uterine activity during the ovulatory cycle causes fixed increased perfusion due to endometrial proliferation (76). Finally, a uterine leiomyoma may show transient, fixed activity due to hypervascularity (77-79).

Renal activity is usually fixed but can confuse interpretation when the activity arises from an unexpected location such as a pelvic or ectopic kidney $(79,80)$, a horseshoe kidney $(81)$, or a renal transplant.

Movement or pooling of urine activity can mimic gastrointestinal bleeding located in the ureter, bladder, or bladder diverticulum (3) or can be caused by urinary diversion surgery. 
Vascular causes of abnormal RBC distribution can include aneurysms of the abdominal aorta, gastroduodenal artery, iliac artery, and other arterial vessels. Vascular grafts can also alter the normal blood pool anatomy. There are several reports of arterial leaks mimicking gastrointestinal bleeding (82-87). In addition, the literature reports a number of case reports demonstrating aortoduodenal fistula rupture (88), hemangiomas in the liver or small bowel $(89,90)$, and abdominal varices $(92,94)$. Varices are most commonly seen as static blood pool structures, but they can also rupture and cause bleeding $(91,93,95)$. The literature also contains a report of visualization of an abnormal ovarian vein (96).

Splenic variants and pathology can cause fixed activity in the form of accessory spleens and splenosis. They can mimic gastrointestinal bleeding if they rupture (97-99).

Activity may be seen in the gallbladder in patients with renal failure or prior transfusions from hepatobiliary excretion of radiolabeled heme. Less commonly, gallbladder activity can be seen with hemobilia (100-105).

There are several other possible causes of increased RBC activity. Bleeding can occur from a pancreatic pseudocyst through the papilla of Vater and into the duodenum (106). A catheter site can cause static activity in the abdominal wall (107). A blush of activity in the bowel may occur because of hyperemia after surgical resection or in Crohn disease (83). Nonenteric bleeding activity can move and accumulate and confuse interpretation, including intraperitoneal hemorrhage $(108,109)$, mesenteric bleeding $(110)$, and soft-tissue hematoma/hemorrhage (111-116). Both benign and malignant neoplasms and metastatic disease can cause hyperemia and bleeding when ulcerated or necrotic (117-126). Retroperitoneal bleeding can show focal uptake that grows in intensity but is not expected to move in a luminal pattern (127).

\section{G. Issues requiring further clarification}

\section{SPECT}

Using planar technique, GIBS may be able only to approximate the site of bleeding. The inherent 3-dimensional nature of SPECT with multiplane reconstruction may yield more accurate localization of a gastrointestinal bleeding site. Comparison of SPECT results to anatomic cross-sectional imaging such as $\mathrm{CT}$ and MR imaging can also help to identify the source of bleeding.

2. SPECT/CT

Software-fused SPECT and CT images can be beneficial but are limited by the potential interval change in bowel location between the 2 modalities (128). The use of dedicated SPECT/CT hybrid cameras can help overcome these shortcomings. Several early studies have suggested that SPECT/CT scanning is able to better pinpoint the site of bleeding that is not well localized or is equivocal on planar images or to differentiate physiologic uptake from pathologic activity (129-131). In one study in which abnormal activity on standard planar scans was evaluated by SPECT/CT, SPECT/CT was required in $37 \%$ of the patients either to precisely localize the site of gastrointestinal bleeding or to exclude gastrointestinal bleeding (131). Although the authors used a 30-min acquisition for the SPECT images, a shorter acquisition $(\sim 15 \mathrm{~min})$ may be adequate.

SPECT/CT can be particularly helpful in the case of slow gastrointestinal bleeding, for which one may have to wait a long time to see the bowel activity conform into a more specific pattern (57). SPECT/CT can also estimate the length of the gastrointestinal tract leading to the bleeding site and therefore help decide which endoscopic approach to use for further evaluation (57). Furthermore, SPECT/CT helps clarify and avoid the pitfalls that can mimic gastrointestinal bleeding (35). More studies are needed to validate these results. No data exist on the use of SPECT/CT when planar GIBS shows no evidence of gastrointestinal bleeding.

\section{DOCUMENTATION/REPORTING}

\section{A. Goals of the report}

Refer to the SNMMI Procedure Standard for General Imaging.

\section{B. Direct communication}

Refer to the SNMMI Procedure Standard for General Imaging.

\section{Written communication}

Refer to the SNMMI Procedure Standard for General Imaging.

\section{Contents of the report}

The first part of the report should identify the study; provide patient demographics, clinical information (indication for the study), and comparison/correlative imaging data; describe the procedure (radiopharmaceutical, administered activity, route of administration, radiolabeling method for RBCs [in vitro, in vivo, or modified in vivo], duration of the acquisition, frame rate, projections acquired, and whether delayed or special images were obtained); and mention the quality and any limitations of the study.

Next, the report should describe the findings.

1. Presence of any baseline vascular, gastrointestinal tract, or solid-organ variants.

2. Characteristics of any abnormal activity (time of onset in relation to injection, shape, intensity in relationship to background liver activity, extent, subjective volume [small, medium, or large], focal or diffuse, stationary activity or movement of activity in gastrointestinal tract [and, if the latter, whether it is curvilinear (small-bowel) or linear (large-bowel), rapid or slow, and antegrade or retrograde]). 
TABLE 1

Radiation Dosimetry in Adults for ${ }^{99 m}$ Tc-RBCs (132)

\begin{tabular}{|c|c|c|c|c|c|}
\hline \multicolumn{2}{|c|}{$\begin{array}{l}\text { Administered activity } \\
\text { (intravenous) }\end{array}$} & \multicolumn{2}{|c|}{$\begin{array}{l}\text { Organ receiving largest } \\
\text { radiation dose (heart) }\end{array}$} & \multicolumn{2}{|c|}{$\begin{array}{l}\text { Effective } \\
\text { dose }\end{array}$} \\
\hline $\mathrm{MBq}$ & $\mathrm{mCi}$ & mGy/MBq & $\mathrm{rad} / \mathrm{mCi}$ & $\mathrm{mSv} / \mathrm{MBq}$ & $\mathrm{rem} / \mathrm{mCi}$ \\
\hline $555-1,100$ & $15-30$ & 0.023 & 0.085 & 0.0070 & 0.026 \\
\hline
\end{tabular}

TABLE 2

Radiation Dosimetry in Children (5 Years Old) for 99mTc-RBCs (132)

\begin{tabular}{|c|c|c|c|c|c|}
\hline \multicolumn{2}{|c|}{$\begin{array}{l}\text { Administered activity } \\
\text { (intravenous) }\end{array}$} & \multicolumn{2}{|c|}{$\begin{array}{l}\text { Organ receiving largest } \\
\text { radiation dose (heart) }\end{array}$} & \multicolumn{2}{|c|}{$\begin{array}{l}\text { Effective } \\
\text { dose }\end{array}$} \\
\hline $\mathrm{MBq} / \mathrm{kg}$ & $\mathrm{mCi} / \mathrm{kg}$ & mGy/MBq & $\mathrm{rad} / \mathrm{mCi}$ & $\mathrm{mSv} / \mathrm{MBq}$ & $\mathrm{rem} / \mathrm{mCi}$ \\
\hline $11.39-26.67$ & $0.31-0.72$ & 0.066 & 0.24 & 0.021 & 0.078 \\
\hline
\end{tabular}

TABLE 3

Dose Estimates to Fetus for 99mTc-RBCs (133)

\begin{tabular}{lcc}
\hline \multirow{2}{*}{ Stage of gestation } & \multicolumn{2}{c}{ Fetal dose } \\
\cline { 2 - 3 } & $\mathrm{mGy} / \mathrm{MBq}$ & $\mathrm{rad} / \mathrm{mCi}$ \\
\hline Early & 0.0068 & 0.025 \\
$3 \mathrm{mo}$ & 0.0047 & 0.017 \\
$6 \mathrm{mo}$ & 0.0034 & 0.013 \\
$9 \mathrm{mo}$ & 0.0028 & 0.010
\end{tabular}

Dose estimates for in vivo or in vitro labeling are only slightly different. The slightly higher values for in vitro labeling are presented here.

3. Location of any abnormal activity (quadrant of abdomen and pelvis, gastric, small bowel [duodenum, jejunum, or ileum], or large bowel [cecum, ascending colon, hepatic flexure, transverse colon, splenic flexure, descending colon, sigmoid colon, or rectum]).

If the bleeding site cannot be definitively localized, then giving an approximate site based on the imaging characteristics is appropriate. If SPECT/CT is used to further localize small-bowel activity, an attempt should be made to approximate the distance from the ampulla of Vater to the bleeding site to help determine which endoscopic technique can be used should gastroenterology be consulted. The ampulla of Vater is located in the medial aspect of the second (descending) portion of the duodenum at the confluence of the common bile duct and pancreatic duct.

Finally the report should give the impression (whether the study was positive or negative for active gastrointestinal bleeding and, for a positive scan, the originating site of gastrointestinal bleeding, if known).

\section{EQUIPMENT SPECIFICATION}

A large-field-of-view $\gamma$ camera equipped with a lowenergy high-resolution collimator is preferred, although a low-energy general-purpose collimator may also be used. When the study must be performed at the bedside, a diverging collimator (if available) is useful to visualize the maximum abdominal and pelvic areas, particularly in large patients. A SPECT or SPECT/CT camera can be used to assist further localization of the gastrointestinal bleeding site.

Refer also to the SNMMI Procedure Standard for SPECT/CT Imaging.

\section{QUALITY CONTROL AND IMPROVEMENT, SAFETY, INFECTION CONTROL, AND PATIENT EDUCATION CONCERNS}

Refer to the SNMMI Procedure Standard for General Imaging.

\section{RADIATION SAFETY IN IMAGING}

Refer also to the SNMMI Procedure Standard for General Imaging. Radiation dosimetry in adults, a 5-y-old child, and the fetus are presented in Tables 1-3.

Administration of radiopharmaceuticals to pregnant, potentially pregnant, or lactating patients is addressed in the SNMMI Procedure Standard for General Imaging. ICRP publication 106, appendix D, suggests that lactating patients who receive in vivo ${ }^{99 \mathrm{~m}} \mathrm{Tc}-\mathrm{RBCs}$ require a $12-\mathrm{h}$ interruption of breast feeding. No cessation of breast feeding is required for patients receiving in vitro ${ }^{99 \mathrm{~m}} \mathrm{Tc}-\mathrm{RBCs}$. The physician must consider the indication for the test, the potential benefit the information may provide, and the potential radiation risk to the mother and fetus.

\section{ACKNOWLEDGMENTS}

The Committee on SNMMI Procedure Standards consists of the following individuals: Kevin J. Donohoe, MD (Chair) (Beth Israel Deaconess Medical Center, Boston, MA); Sue Abreu, MD (Sue Abreu Consulting, Nichols Hills, OK); Helena Balon, MD (Beaumont Health System, Royal Oak, MI); Twyla Bartel, DO (UAMS, Little Rock, AR); David Brandon, MD (Emory University/Atlanta VA, GA); Paul E. Christian, CNMT, BS, PET (Huntsman Cancer Institute, University of Utah, Salt Lake City, UT); 
Erica J. Cohen, DO (Edward Hines VA Hospital, IL); Dominique Delbeke, MD (Vanderbilt University Medical Center, Nashville, TN); Vasken Dilsizian, MD (University of Maryland Medical Center, Baltimore, MD); Steven W. Falen, MD (Northern California PET Imaging Center, Sacramento, CA); Kent Friedman, MD (NYU School of Medicine, New York, NY); James R. Galt, PhD (Emory University Hospital, Atlanta, GA); Bennett S. Greenspan, MD (Medical College of Georgia, Augusta, GA); Jay A. Harolds, MD (Advanced Radiology Services, PC, Grand Rapids, MI); Aaron Jessop, MD (UT MD Anderson Cancer Center, Houston, TX); David H. Lewis, MD (Harborview Medical Center, Seattle, WA); Alan B. Packard, PhD (Boston Children's Hospital/Harvard Medical School, Boston, MA); J. Anthony Parker, MD, PhD (Beth Israel Deaconess Medical Center, Boston, MA); James A. Ponto, RPh, BCNP (University of Iowa, Iowa City, IA); Darko Pucar, MD (Georgia Regents University, Augusta, GA); Lynne T. Roy, CNMT (Cedars/Sinai Medical Center, Los Angeles, CA); Heiko Schöder, MD (Memorial Sloan-Kettering Cancer Center, New York, NY); Barry L. Shulkin, MD, MBA (St. Jude Children's Research Hospital, Memphis, TN); Michael G. Stabin, PhD (Vanderbilt University, Nashville, TN); and Mark Tulchinsky, MD (Milton S. Hershey Medical Center, Hershey, PA).

The EANM Board consists of the following individuals: Fred Verzijlbergen, MD, PhD (Erasmus MC Central Location, Rotterdam, The Netherlands); Arturo Chiti, MD (Istituto Clinico Humanitas, Rozzano Milan, Italy); Bernd J. Krause, MD, PhD (Universitätsklinikum Rostock, Rostock, Germany); Wim Oyen, MD, PhD (Radboud University Medical Centre, Nijmegen, The Netherlands); Valerie Lewington, MD, PhD (Guys Hospital, Kings College, London, United Kingdom); Savvas Frangos, MD (Bank of Cyprus Oncology Center, Strovolos, Nicosia, Cyprus); and Jure Fettich, MD (University Medical Centre Ljubljana, Ljubljana, Slovenia).

\section{REFERENCES}

1. Winzelberg GG, McKusick KA, Strauss HW, et al. Evaluation of gastrointestinal bleeding by red blood cells labeled in vivo with technetium-99m. J Nucl Med. 1979;20:1080-1086.

2. Maurer AH. Gastrointestinal bleeding and cine-scintigraphy. Semin Nucl Med. 1996;26:43-50.

3. Mariani G, Pauwels EK, AlSharif A, et al. Radionuclide evaluation of the lower gastrointestinal tract. J Nucl Med. 2008;49:776-787.

4. Eckstein MR, Athanasoulis CA. Gastrointestinal bleeding: an angiographic perspective. Surg Clin North Am. 1984;64:37-51.

5. Sos TA, Lee JG, Wixson, et al. Intermittent bleeding from minute to minute in acute massive gastrointestinal hemorrhage: arteriographic demonstration. AJR. 1978;131:1015-1017.

6. Moncure AC, Tompkins RG, Athanasoulis CA, et al. Occult gastrointestinal bleeding: newer techniques and diagnosis and therapy. Adv Surg. 1989;22:141-177.

7. Ell C, May A. Mid-gastrointestinal bleeding: capsule endoscopy and push-andpull enteroscopy give rise to a new medical term. Endoscopy. 2006;38:73-75.

8. Gralnek IM. Obscure-overt gastrointestinal bleeding. Gastroenterology. 2005; 128:1424-1430.

9. O’Neill BB, Gosnell JE, Lull RJ, et al. Cinematic nuclear scintigraphy reliably directs surgical intervention for patients with gastrointestinal bleeding. Arch Surg. 2000;135:1076-1081.
10. Suzman MS, Talmor M, Jennis R, et al. Accurate localization and surgical management of active lower gastrointestinal hemorrhage with technetiumlabeled erythrocyte scintigraphy. Ann Surg. 1996;224:29-36.

11. Orecchia PM, Hensley EK, McDonald PT, et al. Localization of lower gastrointestinal hemorrhage: experience with red blood cells labeled in vitro with technetium Tc 99m. Arch Surg. 1985;120:621-624.

12. Raju GS, Gerson L, Das A, et al.; American Gastroenterological Association. American Gastroenterological Association (AGA) Institute technical review on obscure gastrointestinal bleeding. Gastroenterology. 2007;133:1697-1717.

13. Panes J, Bouhnik Y, Reinisch W, et al. Imaging techniques for assessment of inflammatory bowel disease: joint ECCO and ESGAR evidence-based consensus guidelines. J Crohns Colitis. 2013;7:556-585.

14. Bearn P, Persad R, Wilson N, et al. ${ }^{99 \mathrm{~m}}$ Technetium-labelled red blood cell scintigraphy as an alternative to angiography in the investigation of gastrointestinal bleeding: clinical experience in a district general hospital. Ann R Coll Surg Engl. 1992;74:192-199.

15. Shennak MM, Tarawneh MS, Al-Sheikh TM. Upper gastrointestinal diseases in symptomatic Jordanians: a prospective endoscopic study. Ann Saudi Med. $1997 ; 17: 471-474$.

16. Khan O, Singh P, Archibald A, et al. The role of labelled red blood cell scintigraphy in the detection of acute gastrointestinal bleeding. West Indian Med J. 2000;49:298-301.

17. Bural GG, Scheetz M, Laymon CM, et al. Tc-99m red blood cell bleeding scan in a pregnant woman presenting with hematemesis: a brief review of indications and guidelines for radionuclide scans during pregnancy. Clin Nucl Med. 2011;36:987-990.

18. Ohri SK, Desa LA, Lee H, et al. Value of scintigraphic localization of obscure gastrointestinal bleeding. J R Coll Surg Edinb. 1992;37:328-332.

19. Wang CS, Tzen KY, Huang MJ, et al. Localization of obscure gastrointestinal bleeding by technetium $99 \mathrm{~m}$-labeled red blood cell scintigraphy. J Formos Med Assoc. 1992;91:63-68.

20. Brunnler T, Klebl F, Mundorff S, et al. Significance of scintigraphy for the localisation of obscure gastrointestinal bleedings. World $J$ Gastroenterol. 2008; 14:5015-5019.

21. Howarth DM, Tang K, Lees W. The clinical utility of nuclear medicine imaging for the detection of occult gastrointestinal haemorrhage. Nucl Med Commun. 2002;23:591-594.

22. Feingold DL, Caliendo FJ, Chinn BT, et al. Does hemodynamic instability predict positive technetium-labeled red blood cell scintigraphy in patients with acute lower gastrointestinal bleeding? A review of 50 patients. Dis Colon Rectum. 2005;48:1001-1004.

23. Hammond KL, Beck DE, Hicks TC, et al. Implications of negative technetium $99 \mathrm{~m}$-labeled red blood cell scintigraphy in patients presenting with lower gastrointestinal bleeding. Am J Surg. 2007;193:404-407.

24. Kollef MH, O'Brien JD, Zuckerman GR, et al. BLEED: a classification tool to predict outcomes in patients with acute upper and lower gastrointestinal hemorrhage. Crit Care Med. 1997;25:1125-1132.

25. Kouraklis G, Misiakos E, Karatzas G, et al. Diagnostic approach and management of active lower gastrointestinal hemorrhage. Int Surg. 1995;80:138-140.

26. Olds GD, Cooper GS, Chak A, et al. The yield of bleeding scans in acute lower gastrointestinal hemorrhage. J Clin Gastroenterol. 2005;39:273-277.

27. Velayos FS, Williamson A, Sousa KH, et al. Early predictors of severe lower gastrointestinal bleeding and adverse outcomes: a prospective study. Clin Gastroenterol Hepatol. 2004;2:485-490.

28. Smith R, Copely DJ, Bolen FH. ${ }^{99 m} \mathrm{Tc}$ RBC scintigraphy: correlation of gastrointestinal bleeding rates with scintigraphic findings. AJR. 1987;148:869-874.

29. Gutierrez C, Mariano M, Vander Laan T, et al. The use of technetium-labeled erythrocyte scintigraphy in the evaluation and treatment of lower gastrointestinal hemorrhage. Am Surg. 1998;64:989-992.

30. Orecchia PM, Hensley EK, McDonald PT, et al. Localization of lower gastrointestinal hemorrhage: experience with red blood cells labeled in vitro with technetium Tc 99m. Arch Surg. 1985;120:621-624.

31. Robinson P. The role of nuclear medicine in acute gastrointestinal bleeding. Nucl Med Commun. 1993;14:849-855.

32. Van Geelen JA, De Graaf EM, Bronsveld W, et al. Clinical value of labeled red blood cell scintigraphy in patients with difficult to diagnose gastrointestinal bleeding. Clin Nucl Med. 1994;19:949-952.

33. Gunderman R, Leef J, Ong K, et al. Scintigraphic screening prior to visceral arteriography in acute lower gastrointestinal bleeding. J Nucl Med. 1998;39:1081-1083.

34. Markisz JA, Front D, Royal HD, et al. An evaluation of ${ }^{99 \mathrm{~m}} \mathrm{Tc}$-labeled red blood cell scintigraphy for the detection and localization of gastrointestinal bleeding sites. Gastroenterology. 1982;83:394-398.

35. Allen TW, Tulchinsky M. Nuclear medicine tests for acute gastrointestinal conditions. Semin Nucl Med. 2013;43:88-101. 
36. Tatum JL, Burke TS, Hirsch JI, et al. Pitfall to modified in vivo method of technetium-99m red blood cell labeling: iodinated contrast media. Clin Nucl Med. 1983;8:585-587.

37. Sampson CB. Complications and difficulties in radiolabelling blood cells: a review. Nucl Med Commun. 1996;17:648-658.

38. Karelitz JR, Richards JB. Pseudophotopenic defect due to barium in the colon. Clin Nucl Med. 1978;3:414.

39. Rehm PK, Atkins FB, Ziessman HA. Positive technetium-99m-red blood cell gastrointestinal bleeding scan after barium small-bowel study. J Nucl Med. 1996;37:643-645.

40. Siddiqui AR, Schauwecker DS, Wellman HN, et al. Comparison of technetium99m sulfur colloid and in vitro labeled technetium-99m RBCs in the detection of gastrointestinal bleeding. Clin Nucl Med. 1985;10:546-549.

41. Bunker SR, Lull RJ, Tanasescu DE, et al. Scintigraphy of gastrointestinal hemorrhage: superiority of Tc-99m red blood cells over Tc-99m sulfur colloid. AJR. 1984;143:543-548.

42. Bunker SR, Brown JM, McAuley RJ, et al. Detection of gastrointestinal bleeding sites: use of in vitro technetium Tc99m-labeled RBCs. JAMA. 1982;247:789-792.

43. Thorne DA, Datz FL, Remley K, et al. Bleeding rates necessary for detecting acute gastrointestinal bleeding with technetium- $99 \mathrm{~m}$-labeled red blood cells in an experimental model. J Nucl Med. 1987;28:514-520.

44. Maurer AH, Urbain JL, Krevsky B, et al. Effects of in-vitro versus in-vivo red cell labeling on image quality in gastrointestinal bleeding studies. $\mathrm{J} \mathrm{Nucl} \mathrm{Med}$ Technol. 1998;26:87-90.

45. Patrick ST, Gloniak JV, Turner FE, et al. Comparison of in vitro RBC labeling with the Ultra Tag RBC kit versus in vivo labeling. J Nucl Med. 1991;32:242-244.

46. Ponto JA. Salvage of substandard in vitro technetium Tc-99m-labeled red blood cells. J Am Pharm Assoc. 2006;46:401-402.

47. Kuehne R, Reuter E. High RBC labeling efficiency by controlling pretinning with the modified in vivo/in vitro labeling method. J Nucl Med Technol. 1999;27:222-226.

48. Callahan RJ, Froelich JW, McKusick KA, et al. A modified method for the in vivo labeling of red blood cells with Tc-99m: concise communication. $J$ Nucl Med. 1982;23:315-318.

49. Calculation of the administered activity in $[\mathrm{MBq}]$ and $[\mathrm{mCi}]$. European Association of Nuclear Medicine website. http://www.eanm.org/publications/ dosage_calculator.php?navId=285. Accessed September 5, 2014.

50. Lassmann M, Treves ST; EANM/SNMMI Paediatric Dosage Harmonization Working Group. Paediatric radiopharmaceutical administration: harmonization of the 2007 EANM paediatric dosage card (version 1.5.2008) and the 2010 North American consensus guidelines. Eur J Nucl Med Mol Imaging. 2014;41:1036-1041.

51. Currie GM, Towers PA, Wheat JM. Improved detection and localization of lower gastrointestinal tract hemorrhage by subtraction scintigraphy: phantom analysis. J Nucl Med Technol. 2006;34:160-168.

52. Maurer AH, Rodman MS, Vitti RA, et al. Gastrointestinal bleeding: improved localization with cine scintigraphy. Radiology. 1992;185:187-192.

53. Zettinig G, Staudenherz A, Leitha T. The importance of delayed images in gastrointestinal bleeding scintigraphy. Nucl Med Commun. 2002;23:803-808.

54. Emslie JT, Zarnegar K, Siegel ME, et al. Technetium-99m-labeled red blood cell scans in the investigation of gastrointestinal bleeding. Dis Colon Rectum. 1996;39:750-754.

55. Winzelberg GG, Froelich JW, McKusick KA, et al. Radionuclide localization of lower gastrointestinal hemorrhage. Radiology. 1981;139:465-469.

56. Ryan P, Styles CB, Chmiel R. Identification of the site of severe colon bleeding by technetium-labeled red-cell scan. Dis Colon Rectum. 1992;35:219-222.

57. Bentley BS, Tulchinsky M. SPECT/CT helps in localization and guiding management of small bowel gastrointestinal hemorrhage. Clin Nucl Med. 2014; 39:94-96.

58. Currie GM, Towers PA, Wheat JM. A role for subtraction scintigraphy in the evaluation of lower gastrointestinal bleeding in the athlete. Sports Med. 2007; 37:923-928.

59. Patton DD, McNeill GC, Edelman K. Cine scintigraphy for gastrointestinal bleeding. Radiology. 1993;187:582.

60. Seto H, Kageyama M, Wu YW, et al. Sequential subtraction scintigraphy with ${ }^{99 \mathrm{~m} T c-R B C}$ for the early detection of gastrointestinal bleeding. Ann Nucl Med. 1995;9:203-208.

61. Wu Y, Seto H. Clinical value of sequential subtraction scintigraphy with ${ }^{99 m} \mathrm{Tc}-$ RBC for gastrointestinal bleeding. Chin Med J (Engl). 2001;114:69-72.

62. Wu Y, Seto H, Shimizu M, et al. Sequential subtraction scintigraphy with 99Tcm-RBC for the early detection of gastrointestinal bleeding and the calculation of bleeding rates: phantom and animal studies. Nucl Med Commun. 1997;18:129-138.

63. Bunker SR. Cine scintigraphy of gastrointestinal bleeding. Radiology. 1993; 187:877-878
64. Meller J, Schönborn E, Conrad M, et al. Improved detection of gastrointestinal bleeding sites with $99 \mathrm{mTc}$ market autologous erythrocytes and continuous dynamic scintigraphy with cine-mode display [in German]. Chirurg. 2000;71:292-299.

65. Leslie WD, Abrams DN, Billinghurst MW. Elution characteristics of 99Tcmlabelled erythrocytes in relation to scintigraphic detection of gastrointestinal bleeding. Nucl Med Commun. 1991;12:983-992.

66. el-Shirbiny A, Fernandez R, Zuckier LS. Premature extravasation: a bleeding site identified during the dynamic phase of Tc-99m red blood cell bleeding scintigraphy. Clin Nucl Med. 1995;20:691-694.

67. Ng DA, Opelka FG, Beck DE, et al. Predictive value of technetium Tc 99mlabeled red blood cell scintigraphy for positive angiogram in massive lower gastrointestinal hemorrhage. Dis Colon Rectum. 1997;40:471-477.

68. Kan JH, Funaki B, O'Rourke BD, et al. Delayed ${ }^{99 \mathrm{~m}}$ Tc-labeled erythrocyte scintigraphy in patients with lower gastrointestinal tract hemorrhage: effect of positive findings on clinical management. Acad Radiol. 2003;10:497-501.

69. Nwakanma L, Meyerrose G, Kennedy S, et al. Recurrent gastrointestinal bleeding diagnosed by delayed scintigraphy with Tc-99m-labeled red blood cells. Clin Nucl Med. 2003;28:691-693.

70. Gupta S, Luna E, Kingsley S, et al. Detection of gastrointestinal bleeding by radionuclide scintigraphy. Am J Gastroenterol. 1984;79:26-31.

71. Dusold R, Burke K, Carpentier W, et al. The accuracy of technetium-99mlabeled red cell scintigraphy in localizing gastrointestinal bleeding. Am J Gastroenterol. 1994;89:345-348.

72. Jacobson AF, Cerqueira MD. Prognostic significance of late imaging results in technetium-99m-labeled red blood cell gastrointestinal bleeding studies with early negative images. J Nucl Med. 1992;33:202-207.

73. McKusick KA, Froelich J, Callahan RJ, et al. ${ }^{99 \mathrm{~m} T c}$ red blood cells for detection of gastrointestinal bleeding: experience with 80 patients. AJR. 1981;137: 1113-1118.

74. Gupta SM, Spencer RP, Chak SP. Significance of intensity of delayed activity during technetium-99m-RBC gastrointestinal bleeding study. J Nucl Med. 1991;32:2249-2252.

75. Wahl RL, Lee ME. Increased genital uptake of ${ }^{99 \mathrm{~m}} \mathrm{Tc}$ red blood cells: a potential cause of false-positive studies for gastrointestinal bleeding. Eur J Nucl Med. 1984;9:245-246.

76. Karacalioglu O, Ilgan S, Arslan N, et al. Uterine doughnut in early proliferating phase: potential pitfall in gastrointestinal bleeding studies. Ann Nucl Med. 2003; 17:685-687.

77. Gafton AR, Caride VJ. Fibroid uterus confounding the correct localization of active gastrointestinal bleeding during Tc-99m RBC scan. Clin Nucl Med. 2006;31:508-510.

78. Goergen TG. Serendipity in scintigraphic gastrointestinal bleeding studies. Clin Nucl Med. 1983;8:396-399.

79. Infante JR, González FM, Vallejo JA, et al. False-positive results of a gastrointestinal bleeding study caused by an ectopic kidney. Clin Nucl Med. 2000; 25:645-646.

80. Zuckier LS, Patel YD, Kratka PS, et al. Pelvic kidney displacing a sigmoid diverticular bleed: scintigraphic and angiographic correlation. Clin Nucl Med. 1988;13:463-464.

81. Anez LF, Gupta SM. Serendipitous detection of a horseshoe kidney during blood pool imaging for gastrointestinal bleeding. Clin Nucl Med. 1992;17: 132-133.

82. Bunko H, Seto H, Tonami N, et al. Detection of active bleeding from ruptured aortic aneurysm by emergency radionuclide angiography. Clin Nucl Med. 1978;3:276-277.

83. Zuckier LS, Patel YD. Incidental abnormalities detected during scintigraphy for gastrointestinal bleeding. Radiographics. 1990;10:467-481.

84. DeArmas CR Jr, Gilbert HS. Rupture of abdominal aortic aneurysm demonstrated on Tc-99m RBC gastrointestinal bleeding study. Clin Nucl Med. 1995;20:925-926.

85. Duarte PS, Zhuang H, Aldighieri F, et al. Incidental detection of an abdominal aortic aneurysm during evaluation of gastrointestinal bleeding with Tc-99mtagged erythrocytes. Clin Nucl Med. 2002;27:824.

86. Orellana P, Olea E, Lillo R, et al. Gastroduodenal artery aneurysm detected by radionuclide studies. Clin Nucl Med. 1983;8:540-542.

87. Noel AW, Makler PT Jr, Velchik MG, et al. Visualization of arterial grafts on a gastrointestinal bleeding scan. Clin Nucl Med. 1985;10:19-20.

88. Yen CK, Pollycove M, Parker H, et al. Rupture of a spontaneous aortoduodenal fistula visualized with Tc-RBC scintigraphy. J Nucl Med. 1983;24:332-333.

89. Iwata Y, Shiomi S, Otso R, et al. A case of cavernous hemangioma of the small intestine diagnosed by scintigraphy with Tc-99m-labeled red blood cells. Ann Nucl Med. 2000;14:373-376.

90. Taylor RE. Tc-99m-labeled red blood cell scan showing gastrointestinal bleeding point, and also showing an incidental hepatic hemangioma. Clin Nucl Med. 2004;29:211-213. 
91. Moreno AJ, Byrd BF, Berger DE, et al. Abdominal varices mimicking an acute gastrointestinal hemorrhage during technetium- $99 \mathrm{~m}$ red blood cell scintigraphy. Clin Nucl Med. 1985;10:248-251.

92. Karimeddini MK, Dambro TJ, Gabor MP, et al. Omental varices detected on a radionuclide gastrointestinal bleeding study. Clin Nucl Med. 1992;17:672-673.

93. Joo YE, Kim HS, Choi SK, et al. Massive gastrointestinal bleeding from jejunal varices. J Gastroenterol. 2000;35:775-778.

94. Yoshikai T, Yokomizo Y, Iwashita I, et al. Inferior mesenteric varix demonstrated by ${ }^{99 m}$ Tc-red blood cell gastrointestinal bleeding study. Ann Nucl Med. 1997;11:163-166.

95. Hansen ME, Coleman RE. Scintigraphic demonstration of gastrointestinal bleeding due to mesenteric varices. Clin Nucl Med. 1990;15:488-490.

96. Camele RA, Bansal SK, Turbiner EH. Red blood cell gastrointestinal bleeding scintigraphy: appearance of the left ovarian vein. Clin Nucl Med. 1984;9: 275-276.

97. Heyman S, Sunaryo FP, Ziegler MM. Gastrointestinal bleeding: an accessory spleen causing a false-positive Tc-99m-sulfur colloid study. Clin Nucl Med. 1982; 7:38-40.

98. Mavi A, Degirmenci B, Bekis R, et al. Intra-abdominal splenosis mimicking massive gastrointestinal bleeding. Clin Nucl Med. 2003;28:226-227.

99. Champagne C, Powe JE. Incidental detection of ruptured spleen during Tc-99m RBC gastrointestinal bleeding study. Clin Nucl Med. 1992;17:404-405.

100. Abello R, Haynie TP, Kim EE. Pitfalls of a ${ }^{99 \mathrm{~m}} \mathrm{Tc}-\mathrm{RBC}$ bleeding study due to gallbladder and ileal-loop visualization. Gastrointest Radiol. 1991;16:32-34.

101. Brill DR. Gallbladder visualization during technetium-99m-labeled red cell scintigraphy for gastrointestinal bleeding. J Nucl Med. 1985;26:1408-1411.

102. Howarth D, Davidson P. Neonatal gastric hemorrhage showing gallbladder visualization with Tc-99m red blood cell scintigraphy. Clin Nucl Med. 2002;27:524-526.

103. Sato S, Kuwajima A, Watanabe S, et al. Delayed visualization of gallbladder with in vivo labeled Tc-99m-red blood cell scintigraphy for gastrointestinal bleeding. Radiat Med. 1988;6:159-161.

104. Vidal-Sicart S, Lomeña F, Setoain FJ, et al. Gallbladder visualization on RBC scintigraphy. Clin Nucl Med. 1996;21:660.

105. Wood MJ, Hennigan DB. Radionuclide tagged red blood cells in the gallbladder. Clin Nucl Med. 1984;9:289-290.

106. Zanen AL, van Vliet AC, Beukers R. Pancreatic pseudocyst as a cause of upper gastrointestinal bleeding. Neth J Med. 1995;46:90-94.

107. Swayne LC, Schroeder DC, Peterson DP. CAPD catheter site uptake during RBC gastrointestinal bleeding scan. Clin Nucl Med. 1991;16:936-937.

108. Ben-Haim S, Rezai K. Intraperitoneal bleeding demonstrated by Tc-99m labeled red blood cell scintigraphy. Clin Nucl Med. 1992;17:789-790.

109. Czarnecki DJ. Intraperitoneal hemorrhage diagnosed by technetium-99m labeled RBC imaging. Clin Nucl Med. 1986;11:617-618.

110. Orzel JA, Rudd TG, Oreskovich M. Evaluation of traumatic mesenteric hemorrhage in a hemophiliac with Tc-99m labeled red blood cell scintigraphy. J Trauma. 1986;26:1056-1057.

111. Green D, Spies SM, Rana NA, et al. Hemophilic bleeding evaluated by blood pool scanning. Thromb Haemost. 1981;45:208-210.

112. Rosenbaum RC, Johnston GS, Whitley NO. Scintigraphic detection of occult hemorrhage in a patient receiving anticoagulants. J Nucl Med. 1986;27:223-225.

113. Fink-Bennett D, Johnson JR. Gluteal hematoma: a potential cause for a falsepositive Tc-99m RBC gastrointestinal bleeding study. Clin Nucl Med. 1984; 9:414.

114. Gonzalez CE, Fig LM, Cano M, et al. Technetium-99m-red blood cell scintigraphy in the localization of nonenteric hemorrhage. J Nucl Med. 1994;35: 1333-1337.
115. Moreno AJ, Reeves TA, Pearson VD, et al. Unusual manifestations of hemorrhage during technetium-99m red cell blood pool imaging. Clin Nucl Med. 1989;14:470-471.

116. Bunker SR, Kolina JS, Kaplan KA, et al. Scintigraphic detection of occult hemorrhage using RBCs labeled in vitro with technetium Tc $99 \mathrm{~m}$ sodium pertechnetate. Arch Intern Med. 1983;143:1027-1028.

117. Biegel E. Scintigraphic demonstration of bleeding colonic metastasis in a patient with endometrial cancer [in Danish]. Ugeskr Laeger. 1995;157:3337-3338.

118. Swayne LC, Caruana V, Ginsberg HN, et al. Potential false-positive red blood cell gastrointestinal bleeding study secondary to osseous metastasis. Clin Nucl Med. 1991;16:770-771.

119. Gagliano E, Tonante A, Lo Schiavo MG, et al. Ileal leiomyosarcoma presenting with an episode of acute massive intestinal bleeding [in Italian]. Chir Ital. 2006; 58:519-524.

120. Sood R, Tee SI. A predominant pelvic gastrointestinal stromal tumor (GIST) mass observed on Tc-99m red blood cell gastrointestinal bleeding scintigraphy. Clin Nucl Med. 2011;36:e93-e95.

121. Wang J, Zhao R. ${ }^{99 \mathrm{~m}} \mathrm{Tc}-\mathrm{RBC}$ scintigraphy for diagnosis of intestinal stromal tumor hemorrhage: a case report. Int J Clin Exp Pathol. 2012;5:270-273.

122. Caruana V, Swayne LC, Diehl WL. Scintigraphic localization of a bleeding leiomyosarcoma of the proximal jejunum. Clin Nucl Med. 1991;16:230-232.

123. Cortes J, Alonso JI, Ruiz-Oliva F, et al. Renal cell carcinoma detected on Tc99m-labeled red blood cell imaging. Clin Nucl Med. 2003;28:920-922.

124. Joseph UA, Jhingran SG. Technetium-99m labeled RBC imaging in gastrointestinal bleeding from gastric leiomyoma. Clin Nucl Med. 1988;13:23-25.

125. Sanli Y, Adalet I, Turkmen C, et al. Primary lymphoma of the small bowel detected with red blood cell scintigraphy. Clin Nucl Med. 2005;30:490-491.

126. Sun SS, Hsieh JF, Tsai SC, et al. Unexpected detection of colon lymphoma on a Tc-99m-labeled red blood cell abdominal scan. Clin Nucl Med. 2000;25: 1052-1053.

127. Ring DH, Silverman ED. Scintigraphic detection of an occult bleed into a retroperitoneal mass using Tc-99m labeled red blood cells. Clin Nucl Med. 1997;22:765-767.

128. Yama N, Ezoe E, Kimura Y, et al. Localization of intestinal bleeding using a fusion of Tc-99m-labeled RBC SPECT and x-ray CT. Clin Nucl Med. 2005;30:488-489.

129. Schillaci O, Danieli R, Manni C, et al. Is SPECT/CT with a hybrid camera useful to improve scintigraphic imaging interpretation? Nucl Med Commun. 2004;25:705-710.

130. Schillaci O, Spanu A, Tagliabue L, et al. SPECT/CT with a hybrid imaging system in the study of lower gastrointestinal bleeding with technetium-99m red blood cells. Q J Nucl Med Mol Imaging. 2009;53:281-289.

131. Schillaci O, Filippi L, Danieli R, et al. Single-photon emission computed tomography/computed tomography in abdominal diseases. Semin Nucl Med. 2007;37:48-61.

132. International Commission on Radiological Protection. Radiation Dose to Patients from Radiopharmaceuticals. London, U.K.: ICRP; 1999. ICRP Publication 80.

133. Russell JR, Stabin MG, Sparks RB, Watson E. Radiation-absorbed dose to the embryo/fetus from radiopharmaceuticals. Health Phys. 1997;73:756-769.

\section{APPROVAL}

This standard/guideline (version 2.0) was approved by the Board of Directors of the SNMMI on November 17, 2014, and by the EANM Board on September 22, 2014. Version 1.0 was approved on February 7, 1999. 